\title{
Congenitally missing lateral incisors: case management with a multidisciplinary approach
}

\begin{abstract}
The replacement of congenitally missing maxillary lateral incisors can be a challenge from both a prosthetic and surgical perspective. Fixed prosthodontic and removable prostheses, resin bonded retainers, orthodontic movement of maxillary canine to the lateral incisor site and single tooth implants represent the available treatment modalities to replace congenitally missing teeth. This case report demonstrates the team approach in prosthetic and surgical considerations and techniques for managing the lack of lateral incisors. Critical to achieving predictable esthetics and function for congenitally missing maxillary lateral incisors is the close communication between the prosthetic and the surgical team members.
\end{abstract}

\author{
Volume 6 Issue 4 - 2017
}

\author{
Babay N,' Abduljabbar T,' Balqess S, ${ }^{2}$ Bukhary \\ $M T^{3}$ \\ 'Department of periodontics and Community Dentistry, King \\ Saud University College of Dentistry, Saudi Arabia \\ ${ }^{2}$ Department of Prosthetics Dental Sciences, King Saud \\ University College of Dentistry, Saudi Arabia \\ ${ }^{3}$ Department of Pediatrics Dentistry and Orthodontics, King \\ Saud University College of Dentistry, Saudi Arabia
}

\begin{abstract}
Correspondence: Babay N, Department of periodontics and Community Dentistry, King Saud University College of Dentistry, Saudi Arabia, Email nadirbabay@gmail.com
\end{abstract}

Received: September 08, 2016 | Published: February 24, 2017

\section{Summary}

Replacement of maxillary lateral incisors with congenital absence may be a challenge both prosthetically and surgically. Removable dentures, fixed prostheses, r-resin, orthodontic treatment of upper canines at the lateral incisor site and dental implants represent treatment modalities available for replacement of congenitally missing teeth This clinical case demonstrates the multidisciplinary prosthetic and surgical approach to treat the absence of lateral incisors. The close collaboration between the prosthesis and the members of the surgical team is essential for the aesthetic and functional success of agenesis of lateral incisors.

\section{Introduction}

Choosing and achieving a predictable esthetic and functional result for replacing congenitally missing maxillary lateral incisors from orthodontic, prosthetic, and surgical implant perspectives has been explored clinically. ${ }^{1}$ The successful use of dental implants to replace missing teeth has been one of the most popular, exciting and evolving areas of clinical dentistry. ${ }^{1}$ The ideal treatment option is dental implant. An interdisciplinary team approach is therefore recommended as the treatment is becoming more complex for the dental practitioner. An Interdisciplinary approach is required and involve a prosthetic and orthodontic treatment and following consultations with a periodontist or an oral surgeon and the implant modality treatment will be selected. ${ }^{2,3}$ Astra Tech dental implant is a versatile system in such any restorative requirement can be addressed, ${ }^{4}$ The orthodontist must understand the critical parameters of aligning the roots and consultation with the periodontist who will surgically place the dental implants is critical. ${ }^{5,6}$ The Angle Society of Europe addressed controversies relating to the management of the missing lateral incisors. The consensus was that the care of patients with congenitally missing lateral incisors is best achieved through a multi-disciplinary approach. ${ }^{7}$ Implants do not require preparation of natural teeth and therefore can be considered the most conservative approach and their long-term success rates of implants have made them an obvious restorative choice.

\section{Case report}

A 21 year old female was refereed from the orthodontic division, King Saud University college of Dentistry for management of missing laterals (Figure 1A-1C). After orthodontic treatment was finalized, the orthodontic brackets were removed and a removable appliance was used to replace the missing maxillary lateral incisors.

Implant Placement (Figure 2-11) Ridge evaluation and mapping was done under local anesthesia to evaluate bone width and was found to be adequate to accommodate an Osseospeed $\mathrm{S} 3.0 \mathrm{~mm}$ wide, 15 $\mathrm{mm}$ length Astra Tech except in the apical area where the width was narrower therefore leading to some bone exposure. The left lateral was treated identically with an Osseospeed S $3.0 \mathrm{~mm}$ wide, $15 \mathrm{~mm}$ length Astra Tech Company.

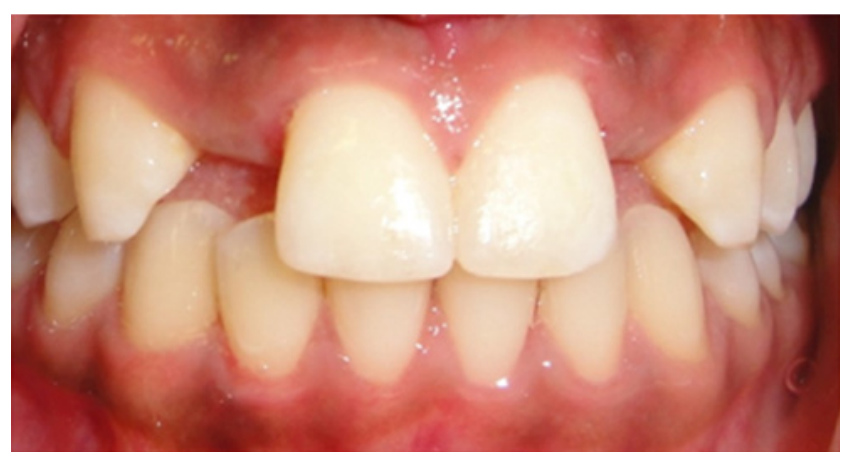

Figure IA Following orthodontic treatment. 


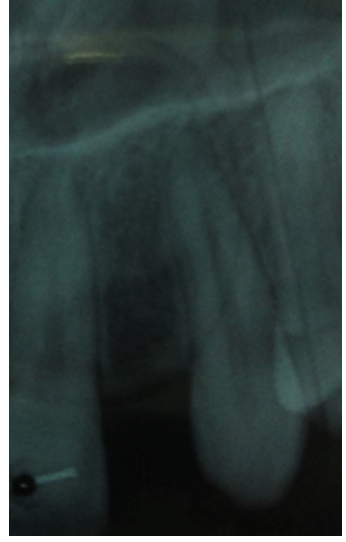

Figure IB X-ray revealing narrow space.

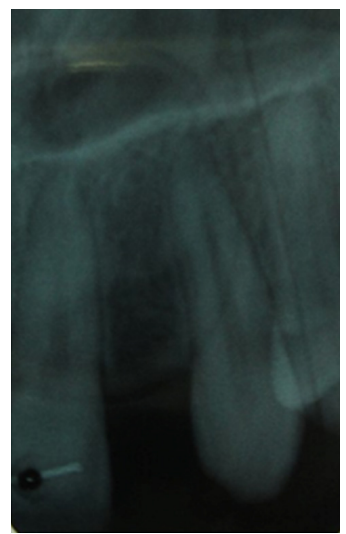

Figure IC Left side space.

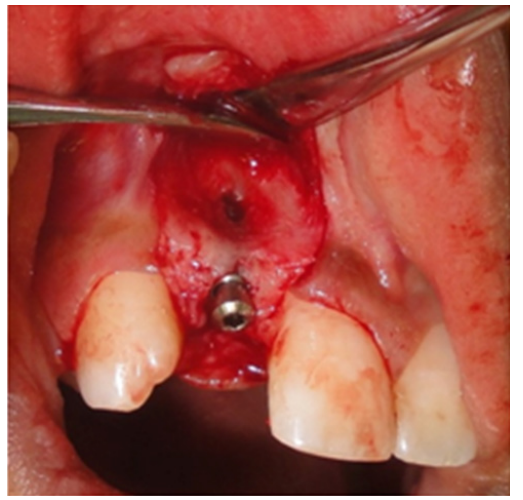

Figure 2 Implant in site with a bone window apically.

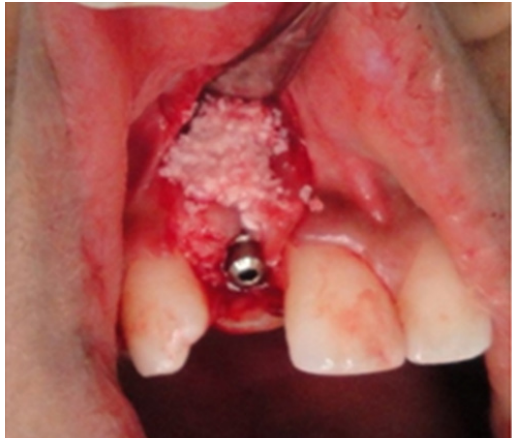

Figure 3 Bioss covering the bone exposure.

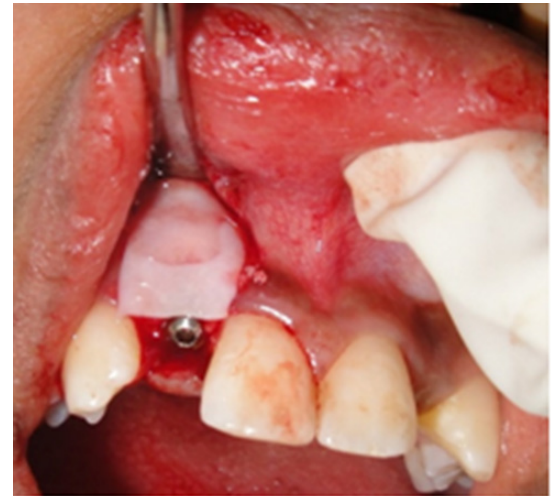

Figure 4 Bioguide membrane to cover the bone.

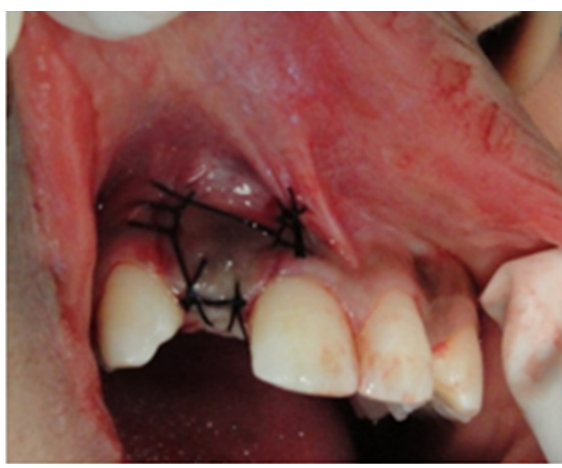

Figure 5 Complete closure with silk sutures.

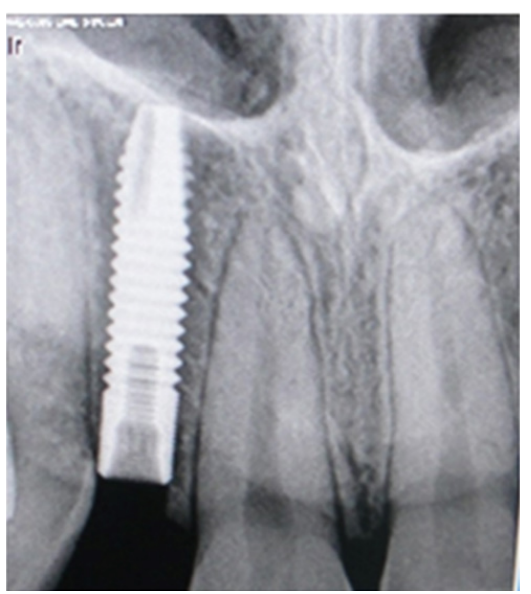

Figure 6 Xray post surgical.

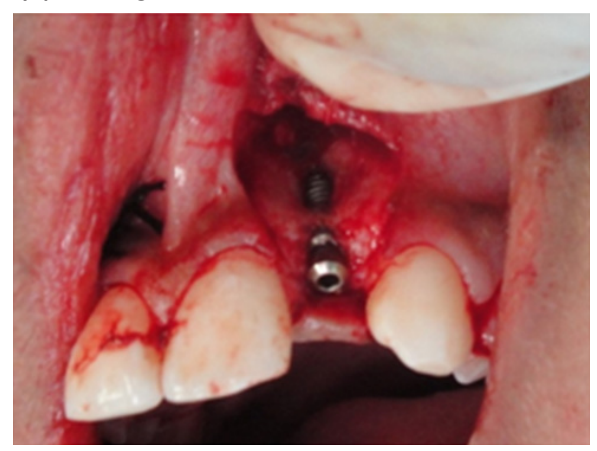

Figure 7 Implant in site with apical bone exposure. 


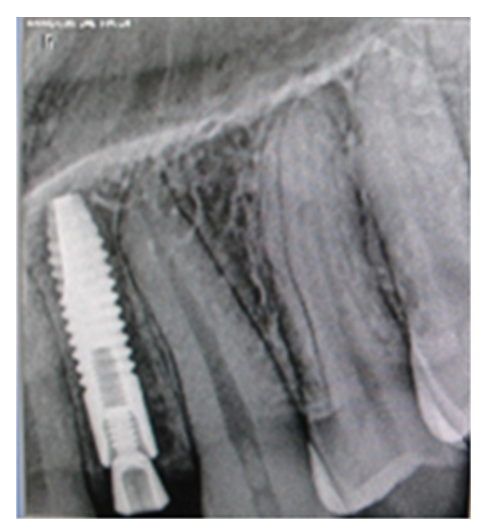

Figure 8 Xray immediately after implant placement.

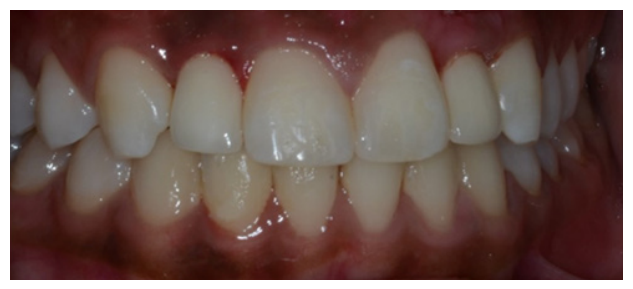

Figure 9 Cement retained implant supported zirconia fused to porcelain crown at 6 months post op.

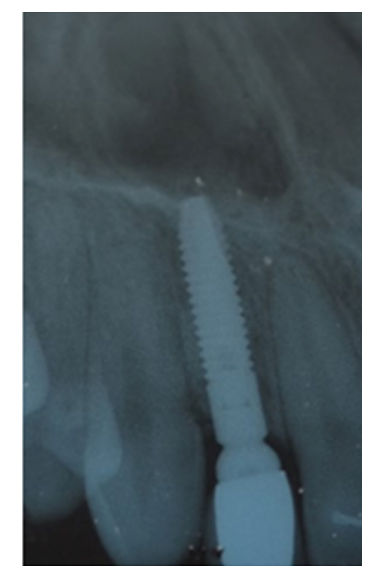

Figure 10 Xray 6 months post op.

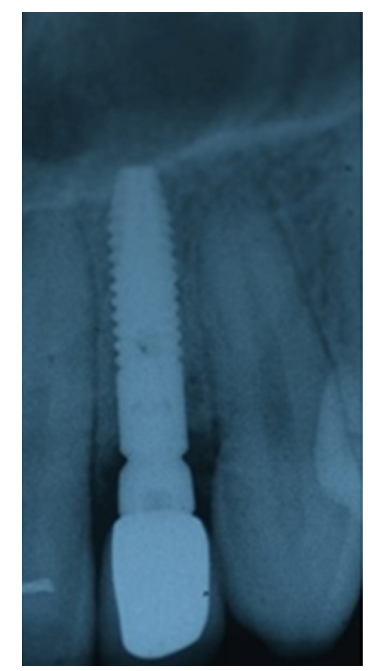

Figure I I Left Side.

\section{Discussion and conclusion}

The Absence of the maxillary lateral incisors in young patients creates an aesthetic problem which can be managed in many ways. The clinical condition requires a multidisciplinary approach with careful treatment planning and a consideration of the options and outcomes following either space closure or prosthetic replacement. ${ }^{8}$ The reason is that dental Implant treatment planning in the case of congenitally missing maxillary lateral incisors depends on space requirements, occlusion and the condition of the neighboring teeth. ${ }^{3}$ The ideal time for placement of fixed prosthesis iswhen the growth of the mandible maxilla and alveolus is complete. If the dental implant restored with a zircnonia such as the case presented in this paper is placed earlier before the growth is complete, the surrounding alveolar bone may continue to develop vertically and adjacent teeth may continue to erupt. It will lead to a disharmony between the gingival margin of the prosthesis and the natural therefore submerging the final prosthesis creating an esthetic and functional problem ${ }^{9}$ It is the multidisciplinary approach that lead to the esthetic and functional success of this clinical case, Taking advantage of the synergy of the working team to maximize each clinician's skill will contribute to the best clinical result for these young patients. This approach when well planned will have high predictability and acceptance by the patient. ${ }^{10,11}$

\section{Funding}

None.

\section{Acknowledgements}

None.

\section{Conflicts of interest}

The authors declare that there is no conflict of interest.

\section{References}

1. Kinzer GA, Kokich VO. Managing congenitally missing lateral incisors. Part II: tooth-supported restorations. J Esthet Restor Dent. 2005;17(2):7684.

2. Graber LW. Congenital absence of teeth: a review with emphasis on inheritance patterns. J Am Dent Assoc. 1978;96(2):266-275.

3. Kinzer GA, Kokich VO. Managing congenitally missing lateral incisors. Part III: single-tooth implants. J Esthet Restor Dent. 2005;17(4):202-210.

4. Makkonen TA, Holmberg S, Niemi L, et al. A 5-year prospective clinical study of Astra Tech dental implants supporting fixed bridges or overdentures in the edentulous mandible. Clin Oral Implants Res. 1997;8(6):469-475.

5. Garg AK. Treatment of congenitally missing lateral incisors: Orthodontics, Bone grafts, and Osseointegrated implants. Dental Implantology Today. 2002;13(2):9.

6. Garib DG, Zanella, Peck S. Associated Dental Anomalies: Case report. $J$ Appl Oral Sci. 2005;13(4):431-436.

7. Johal A, Katsaros C, Kuijpers Jagtman AM. A State of the science on controversial topics: missing maxillary lateral incisors-a report of the Angle Society of Europe 2012 meeting. Angle Society of Europe membership Prog Orthod. 2013;14:20.

8. Kokich VG. Maxillary lateral incisor implants: planning with the aid of orthodontics. J Oral Maxillofac Surg. 2004;62(9 Suppl 2):48-56.

9. Small BW. The use of cast gold pinledge retainers with pontics as an esthetic and functional restorative option in the maxillary anterior. Gen Dent. 2004;52(1):18-20. 
10. Muddugangadhar BC, Amarnath GS, Sonika R, et al. Meta-analysis of Failure and Survival Rate of Implant-supported Single Crowns, Fixed Partial Denture, and Implant Tooth-supported Prostheses. J Int Oral Health. 2015;7(9):11-17.
11. Sumanth KS, Savitha B, Lotwani V, et al. Treating dehiscence during implant placement and loading on angled abutment in maxillary lateral incisor region: a case report. J Indian Prosthodont Sos. 2014;14(Suppl 1):319-322. 